\title{
Clinical and pathological findings in an unusual infantile motor neurone disease
}

\author{
RENATA KOHN \\ From the Department of Pathology, Government Hospital, Assaf Harofe, Zrifin, Israel
}

SUMMARY An unusual motor neurone disease with a characteristic denervation atrophy of muscle is described in an infant. The striking change is a vacuolization of the cytoplasm of the affected ganglion cells in many motor nuclei of spinal cord and brain-stem, and in the claustrum. To our knowledge this disease has not yet been described in man and similar pathological changes have been found only in a certain strain of mice ('wobbler').

This paper presents the clinical and pathological findings in an infant with an unusual form of motor neurone disease which appeared to be present at birth. Morphologically, the disease is characterized primarily by chromatolysis and vacuolization of nerve cells of the motor system in spinal cord and brain-stem. The changes seem to be similar to those seen by Duchen and Strich (1968) in a hereditary motor neurone disease in a strain of mice 'wobbler', but to our knowledge such changes have not yet been described in man.

\section{CASE REPORT}

This was the first child, a boy, of young and healthy parents of Egyptian extraction. There were no known inter-marriages in the family. Pregnancy and delivery were normal. Birth weight was $2,500 \mathrm{~g}$ without evidence of prematurity. The mother noted soon after delivery that the right hand of the child was floppy.

The boy was admitted to hospital at the age of 7 months in order to investigate the cause for his floppy hand. He was not able to sit up. His weight was $5,600 \mathrm{~g}$. The right hand was flaccid and showed some outward rotation. The left hand was somewhat spastic. A subluxation of the left hip joint was found. The electroencephalogram (EEG) was normal. The electromyogram (EMG) (right extensor and flexor carpi muscles) showed an uncharacteristic abnormality, possibly caused by a neurogenic muscular lesion; a primary myogenic lesion could be ruled out. Radiographs of the pelvis showed that the ossification centre on the left side was small, and the acetabulum flat, findings which are compatible with a dysplasia on the left side. The right hand showed 'retardation' in bone age. Skull and thorax were normal.

LABORATORY FINDINGS The plasma contained phosphorus 5.1 and $5.8 \mathrm{mg} / 100 \mathrm{ml}$.; alkaline phosphatase 8 and 6 Bodanski units; calcium $9.5 \mathrm{mg} / 100 \mathrm{ml}$; haemoglobin
$8.5 \mathrm{~g} / 100 \mathrm{ml}$.; leucocytes $9100 / \mathrm{c}$. mm; normal differential count; haematocrit $30 \%$; anisomicrocytosis. Plasma iron was 210 and $160 \mu \mathrm{g} / 100 \mathrm{ml}$.; iron binding capacity 170 and 275; total iron binding capacity 380 and 435; iron saturation 55 and $37 \%$. A Sabin-Feldman test for toxoplasmosis was negative; PPD (Mantoux) negative. Cerebrospinal fluid obtained by lumbar puncture showed: Pandy test negative; protein $49 \mathrm{mg} / 100 \mathrm{ml}$.; $\mathrm{NaCl} 660 \mathrm{mg}$ / $100 \mathrm{ml}$.; glucose $65 \mathrm{mg} / 100 \mathrm{ml}$.; no cells; culture negative.

During his stay in hospital he suffered from bronchopneumonia; his weight dropped to $5,300 \mathrm{~g}$.

The clinical diagnoses at discharge included cerebral palsy, arthrogryposis, ? Erb's palsy.

The second admission was for an upper respiratory tract infection at the age of 9 months. His weight was $5,600 \mathrm{gm}$. He neither sat nor stood and raised his head only with difficulty. When he sat up he tumbled over but it was difficult to say whether this was due to weakness, incoordination, or to the mental retardation which was definitely present. On orthopaedic examination, spontaneous movements, as far as they were present, were normal. Active and passive extension of the knee joints was possible only up to $150^{\circ}$. Abduction of the hip joints was restricted. A scoliosis of the spine was found. The cervical spine was not quite free in motion. There was a definite weakness of the extensor muscles of the right wrist. There was no unequivocal weakness of other muscles. No spasticity was present. Tendon reflexes could not be elicited. The impression after the orthopaedic examination was of arthrogryposis of slight degree'.

His cry had always been very weak. There had always been a discharge of a large amount of saliva from his mouth. Radiographs of oesophagus and stomach were normal. The pupils reacted normally to light.

LABORATORY FINDINGS Blood examination showed haemoglobin 11.6 and $11.3 \mathrm{~g} / 100 \mathrm{ml}$; leucocytes 5,000 and 10,400/c. mm; haematocrit 37 and $35 \%$; anisocytosis, poly- and hypochromasia; BSR $30-50 \mathrm{~mm}$ in the first 
hour. Urine was normal. From the faeces Salmonella $B$ and $O$ were cultured temporarily. The level of haptoglobulins in the blood was $200 \mathrm{mg} / 100 \mathrm{ml}$.; glucose-6phosphate dehydrogenase test was negative.

He remained in hospital for more than two months and was treated for rhinitis, pharyngitis, and eczema of the external ear. His weight on discharge was 5,350 g.

He returned for his third and last admission at the age of 11 months (a few days after his last discharge) with a broncho-pneumonia. The boy died on the fifth day after admission with a severe bronchopneumonia.

NECROPSY FINDINGS The general development did not correspond with the age of the child. Generalized muscular atrophy was present but no definite contractures were seen. The lungs showed evidence of bronchopneumonia. The central nervous system appeared normal macroscopically. The weight of the brain was $720 \mathrm{~g}$ (unfixed). The weight of the other organs was within normal limits.

Histological examination of the central nervous system revealed the following changes: several sections from 16 different levels of the spinal cord were examined. All sections revealed pathological changes which, however, seemed to be more marked in the cervical region. On an average two to four of the nerve cells of the anterior horns, one to two nerve cells of the lateral horns and also two to four of the cells of the column of Clarke were found to be enlarged to about three to four times normal size. Some of these cells showed only central chromatolysis, while others, in addition, showed vacuolization of the cytoplasm. These vacuoles were of different size; there were one to two larger ones, eight to 10 mediumsized, or up to 20 or more very small ones in a cell (Figs. 1-4). They seemed to occur at first at the periphery of the cell and at this stage the nucleus appeared normal. At a later stage the entire cell resembled a multiloculated cyst without recognizable nucleus.

Neuronophagia was occasionally seen (Fig. 5). In the stricken areas several very small degenerated neurones were also seen. No inflammatory or vascular change were observed and no inclusion bodies or pigment were seen within the nerve cells. Special staining (Bielschowsk did not reveal axonal enlargement. Slight dysmyelinatio was present in the fasciculi cuneatus and gracilis as wetb as in the dorsal spinocerebellar tracts of the thoracic cor\& The anterior roots showed poor myelination at most levels.

In the medulla oblongata the same cellular changes were present and were confined to the nucleus of the cranial nerve XII, the nucleus ambiguus, and the motow nucleus of the reticular formation. Within the pons chromatolytic and vacuolated neurones were seen in the nuclei of the cranial nerves V, VI, and VII as well as in the motor nucleus of the reticular formation. The cerebella nuclei and cortex appeared normal. The neurones of the substantia nigra were normal (without pigment); withif the red nucleus about a third of the neurones appeared small and degenerated. Vacuolated cells were not seen here. Quite a few neurones of the claustrum were als $\vec{\theta}$ found to be vacuolated, as were several cells in the amygi daloid nucleus and a few in the lateral thalamic nucleuss. Cerebral cortex (including motor and insular cortex appeared normal.

Skeletal muscles (deltoid, psoas, gastrocnemius, and the small muscles of the right hand) revealed the character istic 'grouped atrophy' of denervation - that is, atropitiou muscle bundles were found next to normal ones (Fig 6 No inflammatory changes, necrosis, or phagocytosis rere seen and internal nuclei were not conspicuous. The gastrocnemius muscle showed a moderate increase it intrafascicular fatty tissue; there was no increased connective tissue. The muscle spindles were normal.

The ganglion cells in the myenteric plexus of the gas intestinal tract were found to be normal. The other organns did not reveal any relevant changes except for an extensive bronchopneumonia.

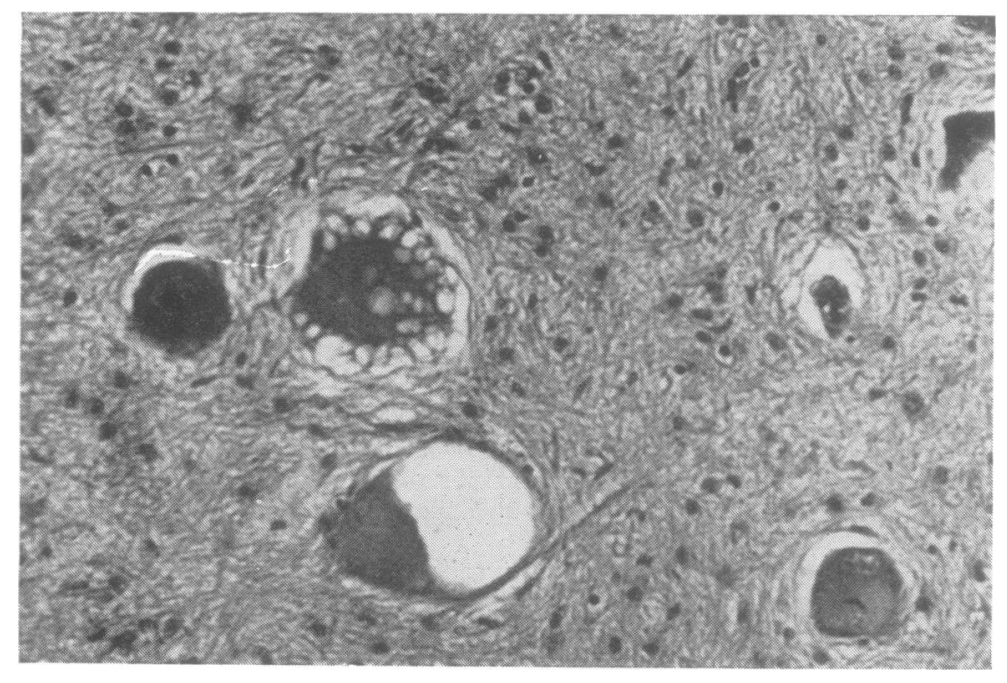

FIG. 1. Neurones of ventral horn of thoracic spinal cord with vacuolization. $H$ and $E$, $\times 400$. 


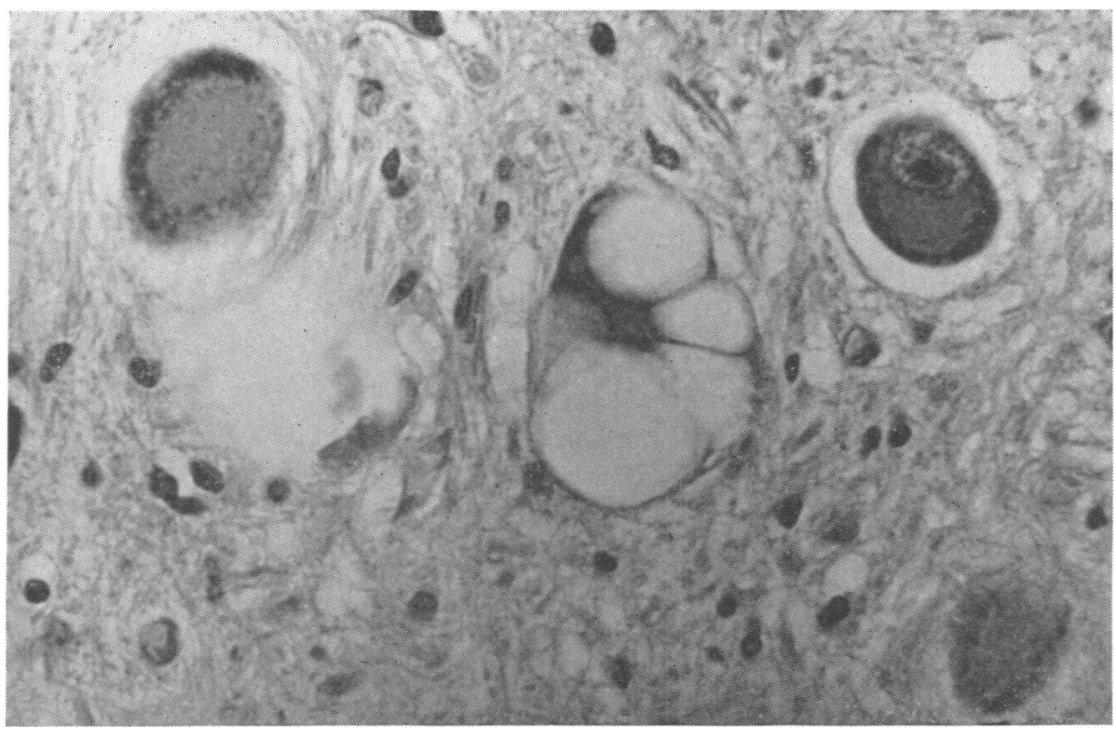

FIG. 2. Vacuolated neurone in hypoglossal nucleus. $H$ and $E$, $\times 800$.

\section{DISCUSSION}

We are dealing here with a disease which involves primarily the motor neurones of the anterior and lateral horns as well as cells of the column of Clarke of the spinal cord, several nuclei in the medulla oblongata, including the motor nucleus of the reticular formation, nuclei in pons and midbrain, and the entire claustrum.

Only the nerve cells themselves are involved and show central chromatolysis and vacuolization of the perikaryon with enlargement of most of the affected cells.
Vacuolization of the cytoplasm, which appears to follow the central chromatolysis, is the most striking change. Scholz (1957) has pointed out that a variety of pathological conditions can lead to vacuolization. He does not think that the formation of vacuoles is an independent process. He describes and illustrates, for example, a somewhat similar but not identical vacuolization in pemphigus. Peters (1949) could produce vacuolization in the cytoplasm of the ganglion cells of the central nervous system with ultrasound. Acute vacuolar change is said by Hager (1968) to occur in experimental viral infections (poliomyelitis, Teschener epidemic in pigs). Srebro (1966)

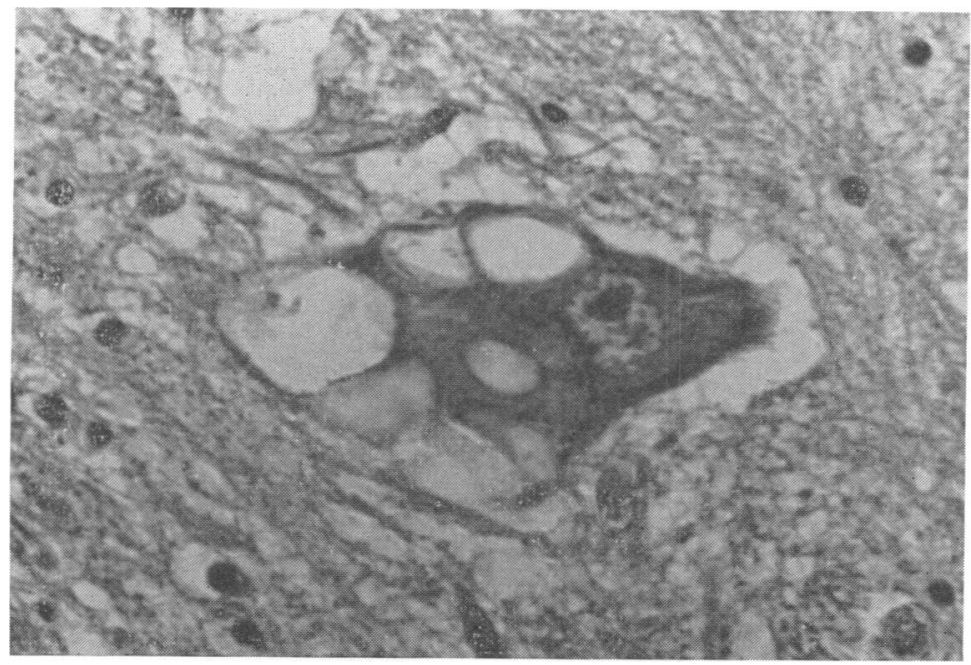

FIG. 3. Vacuolated neurone in Clarke's column. $H$ and $E, \times 800$. 


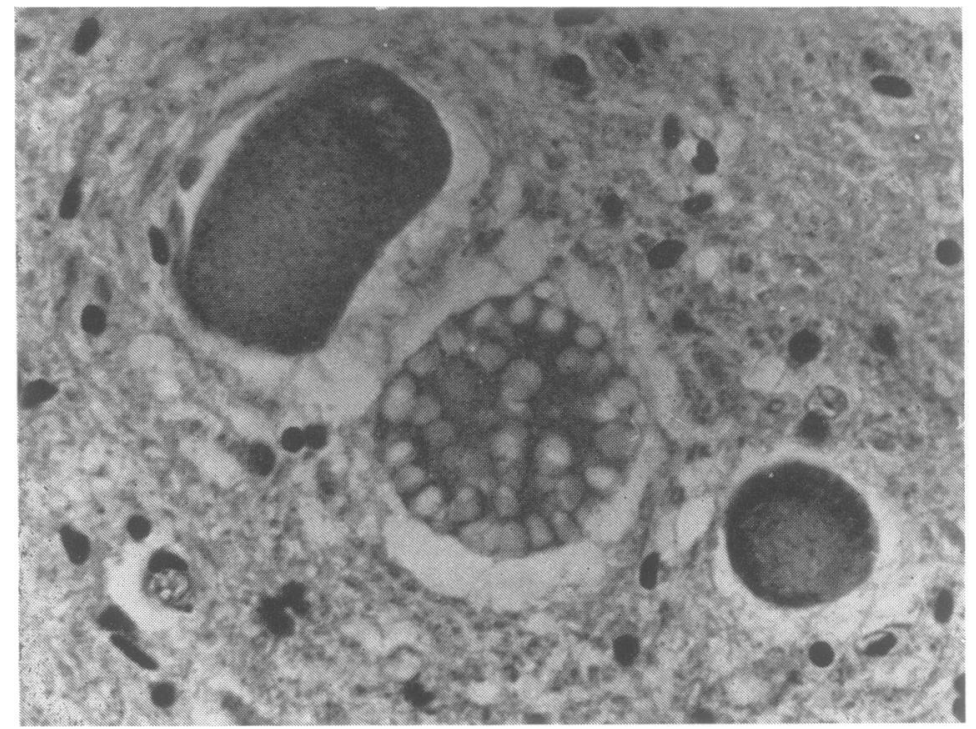

FIG. 4. Anterior horn cell with large number of vacuoles. $H$ and $E, \times 800$.

found large vacuoles in neurones of the septum posterior of the telencephalon in starving frogs. Miller (1959) found that larger vacuoles possibly originate in confluence or rupture of dilated internal spaces of the endoplasmic reticulum. Colmant (1965)

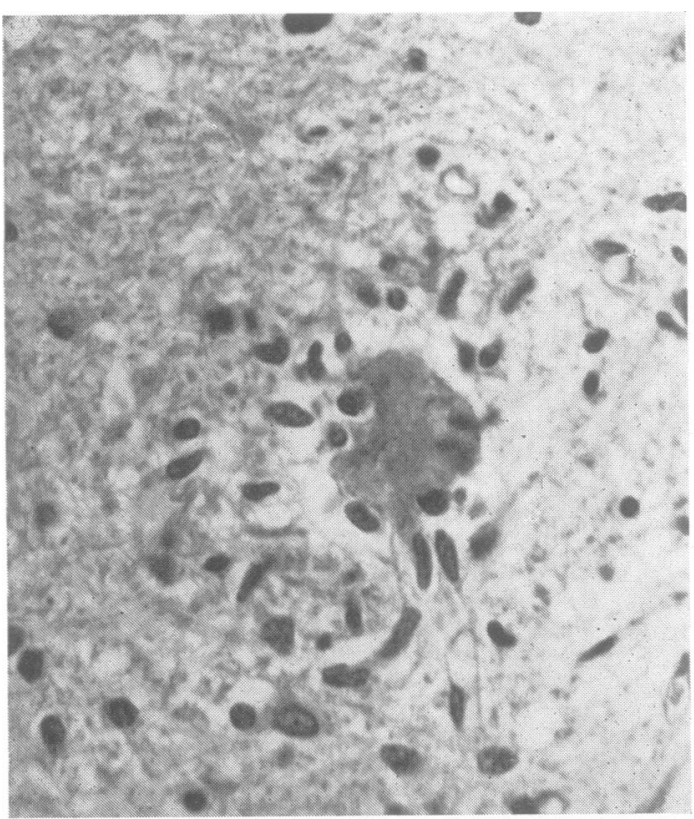

FIG. 5. Neuronophagia in lateral horn of thoracic spinal cord. $H$ and $E, \times 800$. thinks that an acute oxygen deficiency is responsibfe for the occurrence of vacuoles, analogous to the N same process in other organs. He also believes thana confluence of smaller vacuoles leads to the formation of larger ones. The same was proposed previously by Nissl (cited by Kaufmann and Staemmler, 1958) who described the schwere Zellerkrankung in whithe chromatolysis and small vacuoles occur in ganglion? cells of the central nervous system; he also thought 6 oxygen deficiency to be responsible for these changes. -

None of these descriptions and illustrations is identical with the cellular change in the patient presented here. The clinical history and the unusualo distribution - that is, the elective involvement-do not favour a hypoxic aetiology, especially as there ${ }_{\Omega}^{\mathbb{\Phi}}$ are no abnormal findings in the areas usually sen- $\vec{F}$ sitive to hypoxia like the cerebral cortex. Clinical abnormalities were apparently already present at birth and seem to have been progressive. As far aso is known the child did not receive any unusual diet and was not exposed to any toxic or infectious agent.

The neurogenic muscular atrophy fits in well with:the lesions seen in the central nervous system.3. Denervation atrophy was present in all the musclesi examined but appeared to be least marked in the 3 deltoid muscle.

The present disease appears to be different from the motor neurone diseases known so far. The most $\frac{}{2}$ common disease at this age is infantile spinal muscular atrophy (Werdnig-Hoffmann), but in this $N$ we do not find involvement of the lateral horns or the column of Clarke or of the claustrum. Furthermore, vacuolization is not one of the histologicale 


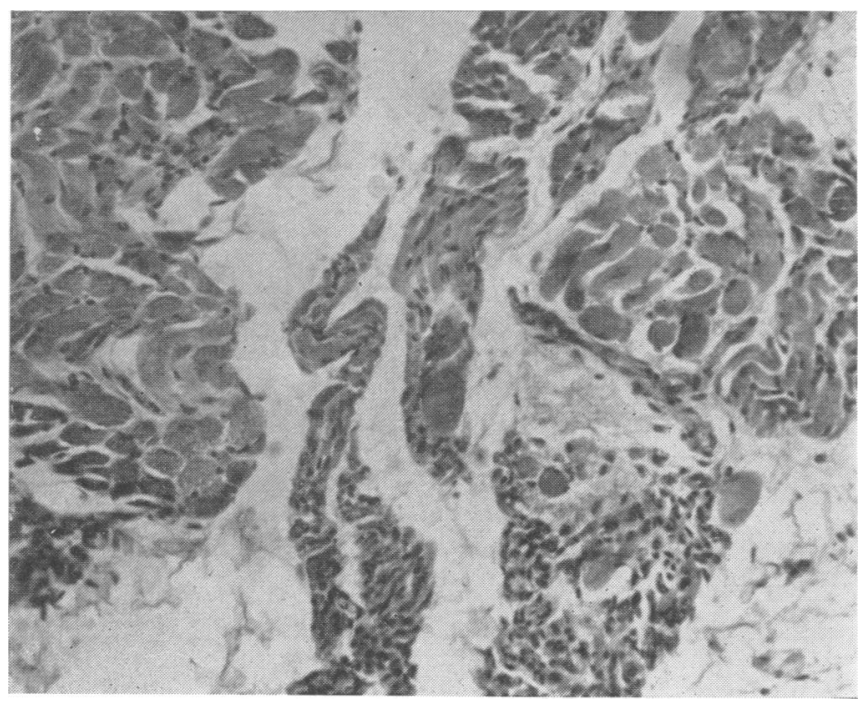

FIG. 6. Denervation atrophy of psoas muscle. $H$ and $E, \times 105$.

features of Werdnig-Hoffmann disease. Hereditary proximal muscular atrophy (Wohlfart-KugelbergWelander) is unlikely to occur at this age and the course is much slower. In this disease we found only degenerative changes without vacuolization in the anterior horn cells accompanied by demyelination of anterior roots and peripheral nerves (Kohn, 1968).

The disease described here does, however, show similarity to an hereditary neurological disease in mice which was described by Duchen and Strich (1968). In this the primary abnormality is also located in the perikaryon of motor neurones with a resulting progressive denervation atrophy of muscle. The disease, called 'wobbler' (because of the wobbling type of gait) was the result of a spontaneous mutation and is transmitted by a single autosomal recessive gene. The main histological changes were striking vacuolization of ventral horn cells in the spinal cord and brain-stem and of cells of the motor nucleus of the reticular formation. The distribution of the affected cells, including nuclei of the reticular system, thus corresponds with that seen in our case, in which, however, the claustrum was also markedly involved.

One has to be cautious in comparing the findings in diseases occurring in experimental animals and in man. In the absence of any known exogenous factors or an abnormal family history it is possible that the disease in our patient was the result of a new mutation.
My thanks are due to Dr. Sabina J. Strich, Institute of Psychiatry, The Maudsley Hospital, London, for her encouragement and invaluable help in preparing this paper.

\section{REFERENCES}

Colmant, H. J. (1965). Zwanglose Abhandlungen aus dem Gebiet der normalen und pathologischen Anatomie. 16. Zerebrale Hypoxie. Thieme: Stuttgart.

Duchen, L. W., and Strich, S. J. (1968). An hereditary motor neurone disease with progressive denervation of muscle in the mouse: the mutant 'wobbler'. J. Neurol. Neurosurg. Psychiat., 31, 535-542.

Hager, H. (1968). Handbuch der allgemeinen Pathologie. Vol. 3, part 3, pp. 62-66. Springer: Berlin.

Kohn, R. (1968). Postmortem findings in a case of WohlfartKugelberg-Welander Disease. Confin. neurol., 30, 253-260.

Miller, F. (1959). Orthologie und Pathologie der Zelle im elektronenmikroskopischen Bild. Verh. dtsch. path. Ges., 42, 261-332.

Nissl, F. cited by Kaufmann, E. and Staemmler, M. (1958). Lehrbuch der speziellen pathologischen Anatomie, 3, part 1. Walter de Gruyter: Berlin.

Peters, G. (1949). Morphologische Untersuchungen ueber die Wirkung von Ultraschallwellen auf das Zentralnervensystem. Fortschr. Neurol. Psychiat., 17, 85.

Scholz, W. (1957). Handbuch der speziellen pathologischen Anatomie. XIII/I. Springer: Berlin.

Srebro, Z. (1966). Electron microscopic observations on vacuolated neurons in starved Rana esculenta. J. comp. Neurol., 126, 1, 65-74. 